\title{
ASSESSMENT OF MEDICAL, NURSE AND MIDWIFE STUDENTS OF THEIR TRAINING IN COMMUNICATION SKILLS
}

\section{Tsvetelina Valentinova, Magdalena I. Balashkova, Vania M. Nedkova-Milanova, Lyubomira D. Gadjelova}

Department of General Practice, Forensic Medicine and Deontology, Faculty of Public Health, Medical University - Pleven

\section{Corresponding author:}

Tsvetelina Valentinova

Department of General Practice, Forensic Medicine and Deontology, Faculty of Public Health, Medical University - Pleven 1, St. Kliment Ohridski Str. Pleven, 5800

Bulgaria

e-mail:tsvm2002@yahoo.com

Received: October 30, 2014

Revision received: March 14, 2015

Accepted: December 01, 2015

\begin{abstract}
Summary
This study aimed to investigate the opinion of students of medicine, nursing and midwifery on their training in communication skills as an optional course. The participants included in the study were 126 students altogether. Information was gathered using a selfadministered questionnaire. The results showed the level of motivation to participate in the training process, the results desired and achieved by the students and their evaluation of the quality of the training. The respondents were convinced that such training would be an asset for their future work as medical professionals and they were satisfied with the quality of training.
\end{abstract}

Key words: communication skills, training, medical, nursing and midwifery students

\section{Introduction}

Communication between health professionals is a process that remains important despite of constantly increasing technology implementation in making diagnoses and treatment undertaken. Good communication is an important aspect throughout the health care process and involves all members of the medical team [1-7]. That is why the quality of training in communication skills of future medical professionals is very important and studies in this field are aimed at assessing these skills. The methods usually used for data collection are self-administered questionnaires [1, 3-5, 8-13].

The aim of this study was to investigate the opinion of students on communication skills as an optional discipline.

\section{Material and Methods}

The study group included students of medicine, nursing and midwifery, participating in communication skills training as an optional course at the Sector of General Medicine, Medical University - Pleven in the 2013/2014 academic year. The study group distribution is shown in Table 1 . The method used for data collection was selfadministered questionnaire. Data were processed with Statgraphics Plus 4.1 for Windows and Microsoft Office Excel. 
Table 1. Participants in the research

\begin{tabular}{ccc}
\hline Students & Number & Percent (\%) \\
\hline Distribution by specialties: & & \\
Medicine & 72 & $57 \%$ \\
Nurse & 22 & $18 \%$ \\
Midwifery & 32 & $25 \%$ \\
\hline Distribution by years: & 32 & $25 \%$ \\
First year students & 72 & $57 \%$ \\
Second year students & 22 & $18 \%$ \\
Third year students & & \\
& & \\
Distribution by gender: & 18 & $14 \%$ \\
Males & 108 & $86 \%$ \\
\hline
\end{tabular}

\section{Results}

The students from the whole study group were certain that their training in communication skills is necessary for success in their future career $\left(\chi^{2}=0.27 ; \mathrm{p}=0.6004 ;\right.$ Figure 1$)$.

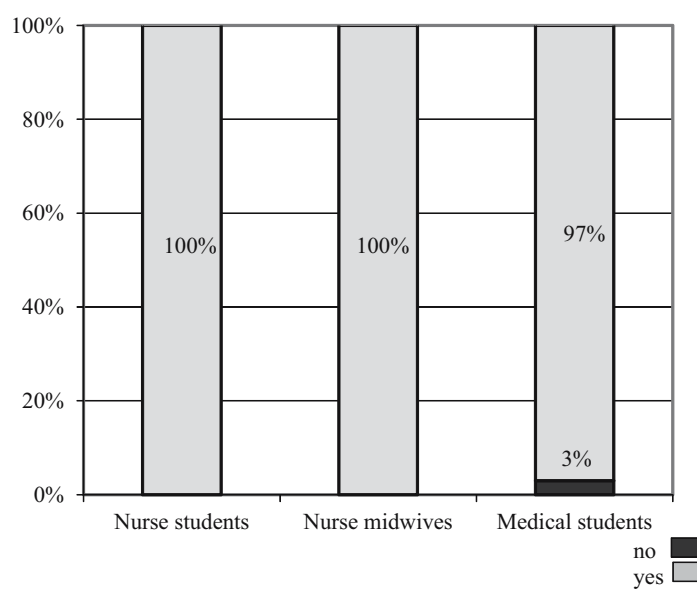

Figure 1. Is communication skills training necessary for your future work?

The students pointed out three main reasons for choosing this course: to be more useful to their patients, to be well prepared as specialists and the realised need of better professional communication skills (Figure 2).

The majority of students answered that they wanted to be able to facilitate the process of starting communication with new patients and be able to deal with difficult patients. The second most popular answer was their desire to improve their communication skills - asking questions, explaining, active listening (Figure 3).

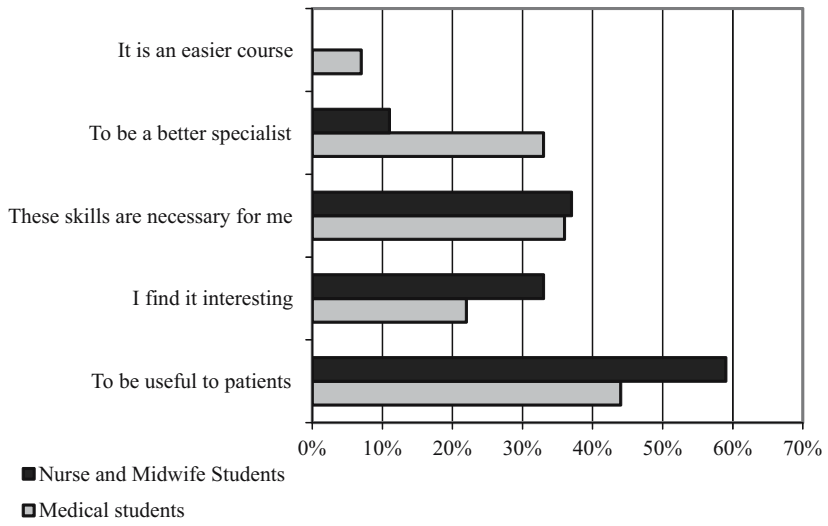

Figure 2. Reasons to choose to study this discipline. Note: The participants have chosen more than one answer.

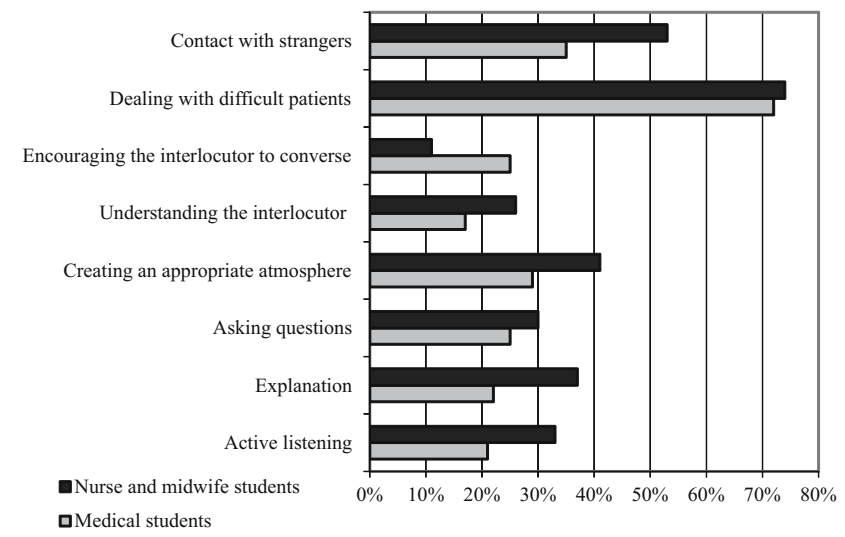

Figure 3. Desired communication skills as a result from the training. Note: The participants have chosen more than one answer.

The preferred form of training was a mixed one - containing both theory and practice (Figure $4)$. 


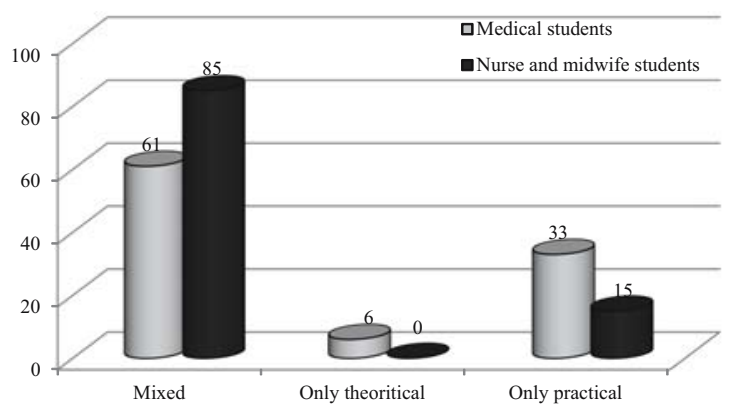

Figure 4. The preferred form of training

Evaluation by the medical students after completion of training:

- Fully corresponding to their preliminary expectations $-36(50 \%)$;

- There were partial differences between reality and expectations $-23(32 \%), 4 \%$ of this group specified that the differences were positive, as some psychological elements of communication were added, which proved to be interesting for them;

- They had not had any preliminary expectations $-13(18 \%)$.

Level of acquired communication skills was assessed on a 1-10 scale:

- At the beginning of the course - average rating $6.58 \pm 0.38$;

- At the end of the course - average rating $7.95 \pm 0.39(\mathrm{~W}=1436 ; \mathrm{p}<0.001)$.

Improvement of the communication skills in some of the desired aspects is presented in Figure 5.

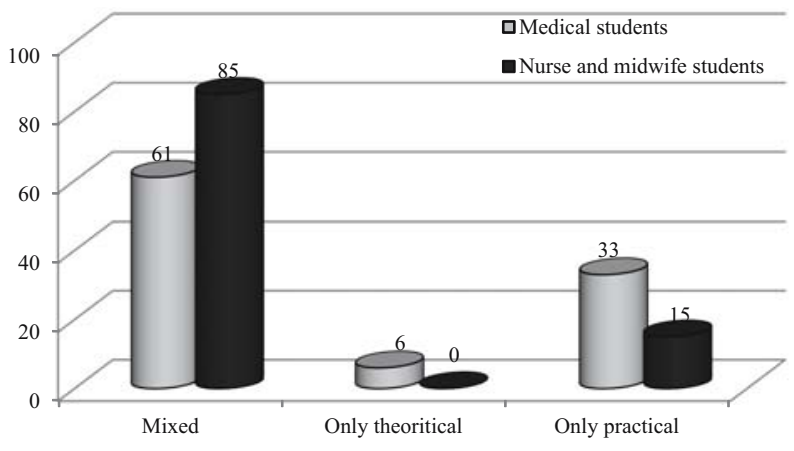

Figure 5. Desired and acquired communication skills during the training. Note: The participants have chosen more than one answer.
When asked for suggestions about improvement of the course in communication skills, $36 \%$ of the study group answered that they did not recommend any changes. The majority of the other students suggested that further augmentation of the practice-oriented tasks, roleplaying games and cases that simulate real-life situations from everyday practice be used for the confirmation of the communication skills acquired.

\section{Discussion}

Our results are similar to those from other studies on the subject $[1,3-5,7-13]$ and showed that students from the three specialities assessed the need of this education. They expressed high satisfaction from the course of communication skills. Medical students were highly satisfied with the training, and also pointed out a positive effect on their communication skills in communication in general, especially about establishing a contact with strangers, keeping a suitable atmosphere for a conversation and possessing the basic communication skills for good communication with patients. Although this evaluation is subjective, it shows that the students feel more confident in their own communication skills after the training, which is a prerequisite for being confident and efficient in the process of communication. For most of the participants, the training programmes fully corresponded to their preliminary expectations. Suggestions for improvement involved including more role-play games and cases, simulating real-life situations.

\section{Conclusion}

Students from the whole study group recognized the importance of the communication skills course for their future work. Their motivation to complete the training course was high and they would like to receive additional information about:

- socialization with new patients;

- dealing with difficult patients in medical practice;

- improvement of basic communication skills needed for medical consultation. 


\section{References}

1. Andonova A, Nikolova M. [Communicational skills of the students - factor which is improving the quality of the health cares]. Proceedings of the 20-th Anniversary International Scientific Conference; 2010 June 3-4; St. Zagora, Bulgaria; Medical Biology Studies III:1-5. Bulgarian.

2. Marinova E. [Communication as an interaction]. Philosophy. 1993(5):39-43. Bulgarian.

3. O'Leary Counahan D. The need for an emphasis on communication in medical training: if you can't communicate you can't be a good doctor. MSJA. 2012;4(1):62-4.

4. Gosbee J. Communication among health professionals. BMJ. 1998;316:642.

5. Yedidia MJ, Gillespie CC, Kachur E, Schwartz MD, Ockene J, Chepaitis AE, et al. Effect of communications training on medical student performance. JAMA. 2003;290(9):1157-65.

6. Levinson W, Lesser CS, Epstein RM. Developing physician communication skills for patientcentered care. Health Aff. 2010;29(7):1310-8.

7. Williams SJ, Calnan M. Key determinants of consumer satisfaction with general practice. Fam Pract. 1991;8:237-42.

8. Abdullatif Alnasir F, Jaradat AAK. The effect of training in primary health care centers on medical students' clinical skills. ISRN Family Med. [Internet]. 2013;[about 5 p.]. Available from: http://dx.doi.org/10.5402/2013/403181.
9. Lowers S. Teaching communication skills to medical students in a virtual world. The Journal of interactive technology\& pedagogy [Internet]. 2013;(3). Available from: http://jitp.commons.gc.cuny.edu/teachingcommunication-skills-to-medical-studentsin-a-virtual-world/.

10. Rees C, Sheard C, Davies S. The development of a scale to measure medical students' attitudes towards communication skills learning: The communication skills attitude scale (CSAS). Med Educ. 2002;36:141-7.

11. Roter DL, Stewart M, Putnam SM, Lipkin M Jr, Stiles W, Inui TS. Communication patterns of primary care physicians. JAMA. 1997;277:350-6.

12. Williams S, Sa B, Nunes P, Stevenson K. Communicating with first year medical students to improve Communication Skills teaching in The University of the West Indies. Int J Med Educ. 2010; 1:5-9.

13. Wrght KB, Bylumd C, Ware J, Parker P, Query JL, Baile W. Medical student attitudes toward communication skills training and knowledge of appropriate provider-patient communication skills: A comparison of firstyear and fourth-year medical students. Med Educ Online. 2006;11: [about 10 p.]. Available from http://www.med-edonline.org 